\title{
Carolina Maria de Jesus e Arthur Bispo do Rosário: uma poética de sucatas na construção da identidade artística
}

\author{
Raffaella Andréa Fernandez ${ }^{1}$
}

Reinscrição de si através da arte ${ }^{2}$

[Bispo]: Igual a essas miniaturas que eu fiz, permite a minha transformação. [Denizart]: Como é que permite? [Bispo]: Não tem a representação? Vou me apresentar corporalmente. Minha ação corporal é esse brilho que eu botei. ${ }^{3}$

Aos 29 anos de idade, Arthur Bispo do Rosário teve um surto psicótico na cidade do Rio de Janeiro, dizendo que possuía uma cruz branca nas costas, uma aura azul e a missão de criar um pequeno "mundo melhor", por ele reinado e que seria entregue a Deus no dia de sua morte. Sua morte seria também a nunciação do fim do mundo, assim partiria em sua camanave levando apenas aqueles escolhidos e inscritos num bordado elaborado em trapos, como partes da matéria do mundo reconfeccionados por ele a partir de materiais sucateados, como pedaços de tecido retirados do lixo ou ganhados, tijolos, vidros, arames, madeiras, latas.

Quando jovem, no auge da loucura, saiu peregrinando pelas igrejas cariocas até chegar na Candelária, quando foi levado para a "Colônia Juliano Moreira", localizada na praia Vermelha-Rio de Janeiro, onde viveu por mais de 50 anos. Nessa instituição ficou encerrado por sete anos numa cela forte ou "quarto de despejo", acepção caroliniana, criando um verdadeiro legado para as artes plásticas e para a humanidade. Além de romper com os conceitos acerca da arte, hoje suas obras são consideradas relíquias da arte contemporânea.

Antes, porém, trabalhou como borracheiro na empresa de luz Light, foi lutador de box, marinheiro e trabalhou como empregado nos anos de 1940, junto a uma tradicional família carioca, os Leoni, que o assessorou juridicamente quando foi atropelado pela empresa Light. Essa família era

\footnotetext{
${ }^{1}$ Doutora em teoria e história da literatura pela Universidade Estadual de Campinas (Unicamp), Campinas, SP, Brasil. E-mail: raffaellafernandez@yahoo.com.br

${ }^{2}$ Este trabalho tem origem em comunicação apresentada durante o XIII Encontro da ABRALIC, realizado entre os dias 10 a 12 de outubro de 2012, em Campina Grande (PB).
}

${ }^{3}$ Extraído do documentário Prisioneiro da passagem (1982). 
um referencial para Bispo do Rosário, sempre que fugia da colônia retornava à casa da família.

Apesar de ter sido catalogado como esquizofrênico no manicômio em que viveu, curiosamente, Bispo do Rosário exerceu o papel de xerife dentro do hospício: um intermediário entre funcionários e internos que auxiliava na manutenção e disciplina do lugar. Entre o final do século XIX e início do século XX, era comum que netos e filhos de ex-escravos, marginalizados pelo mundo do trabalho no processo de construção da "modernização brasileira", fossem enviados para prisões e hospícios como "criminosos", "loucos" ou "vândalos". Tratava-se de um mecanismo prático de discriminação que tinha o objetivo de retirá-los das vistas da sociedade, encobrindo o "problema". Fatalmente, em meio a torturas e a medicamentos, além de toda sorte de desgraças que os manicômios tradicionais oferecem, esses prisioneiros acabavam entregando-se às regras desse ambiente opressor. Apesar disso, movimentos terapêuticos "alternativos" emanciparam esses excluídos acantonados, restituindo-lhes a humanidade pela via da arte-terapia. ${ }^{4}$ Foi assim, por meio das artes plásticas, que Bispo do rosário encontrou o melhor remédio para tratar sua condição de marginalização.

A escritora Carolina Maria de Jesus, também descendente de exescravos, favelada e catadora de lixo teve, assim como Bispo do Rosário, certo reconhecimento em vida com a publicação de seu best seller Quarto de despejo (1960). Sua trajetória e seu processo criativo em muito se assemelham aos de Bispo do Rosário. Ao cotejarmos esses trabalhos, observamos pontos de confluência, fundamentalmente a composição por fragmentos que une o tradicional ao moderno, o antigo ao novo, como partículas desconexas na construção de sentidos avessos, significantes outros e substâncias enviesadas e estranhas ao "bom gosto" estético para compor essas duas estéticas da ordinariedade.

Bispo e Jesus colocaram em funcionamento um tipo muito característico dessas artes produzidas nas margens. Expunham a desestrutura sócio-política de um país periférico que vivia sob um golpe

\footnotetext{
${ }^{4}$ Destaco o papel desempenhado por psiquiatras comprometidos com a recusa a técnicas agressivas de tratamento psiquiátrico, como, entre outros médicos, Nise da Silveira (aluna de Carl Jung e membro-fundadora da Sociedade Internacional de Expressão Psicopatológica). Nise lutou contra as práticas de eletrochoque, insulinoterapia e lobotomia e sua atuação foi de vital importância para reconfigurações conceituais da loucura e, consequentemente, de suas formas de tratamento.
} 
militar, enquanto o mundo explodia pela emancipação das maiorias silenciosas (Baudrillard, 1985).

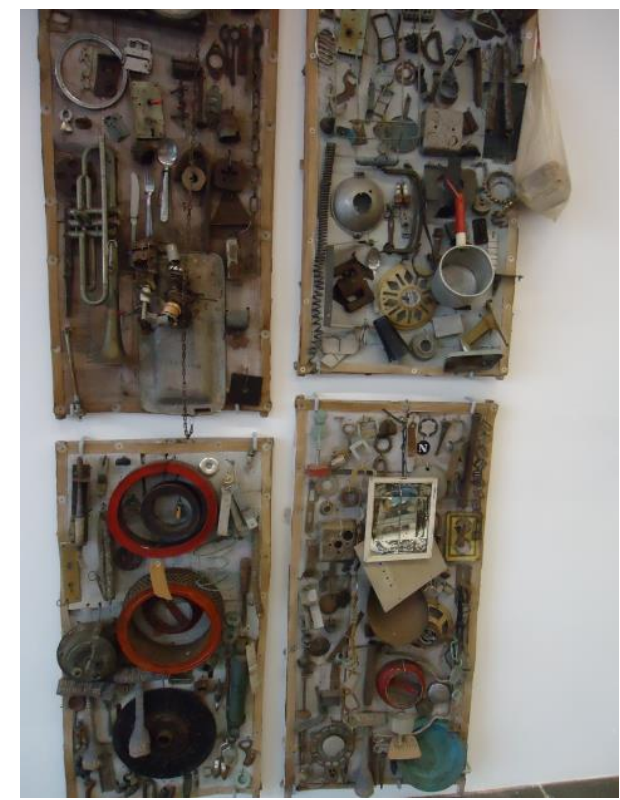

Figura 1 - Registro de passagem pelo mundo. ${ }^{5}$

Enquanto, por exemplo, Bispo do Rosário reúne talheres de diversas épocas numa de suas assemblages, ${ }^{6}$ Carolina de Jesus agrupa em seus manuscritos tanto as falas semi ou nada alfabetizados dos favelados quanto as frases em linguagem culta, presentes nos livros dos românticos ou realistas que a escritora encontrava no lixo ou ganhava de pessoas que apoiavam sua dedicação pela literatura. Do mesmo modo, Bispo do Rosário reutilizava objetos encontrados no lixo do

\footnotetext{
${ }^{5}$ Todas as imagens aqui elencadas foram tiradas pela autora deste artigo na XXX Bienal de São Paulo, realizada no Parque do Ibirapuera em 2012, na qual Bispo do Rosário foi artista homenageado.

${ }^{6}$ Segundo o Dicionário Oxford de Arte (2001, p. 32), entende-se por assemblage: "Termo cunhado em 1950 por Jean Dubuffet, denotativo de obras de arte elaboradas a partir de fragmentos de materiais naturais ou fabricados, como o lixo doméstico, empregados sem qualquer precisão, e já foi usado para definir desde a fotomontagem até instalação em geral. Ganhou uso corrente com uma exposição chamada The Art of Assemblage, realizada no Moma, Nova York, em 1961”.
} 
hospital ou provenientes de algumas andanças, além do material que passou a receber da instituição como doação, quando descoberto em seu "quarto de despejo" imerso em suas criações.

Outra característica em comum é a repetição temática, dada, no caso de Bispo do Rosário, pela disposição sequencial de objetos utilizados por pessoas com as quais ele convivia e, no de Carolina de Jesus, pelas várias versões de um texto manuscrito para narrar um mesmo acontecimento. ${ }^{7}$ Aspectos da arte serial ${ }^{8}$ presente nessas poéticas de sucatas marcam a expressão do desejo de cartografar espaços enxovalhados, fatos históricos "menores" e o movimento do próprio processo criativo na promoção do entendimento e do reconhecimento de suas próprias vidas.

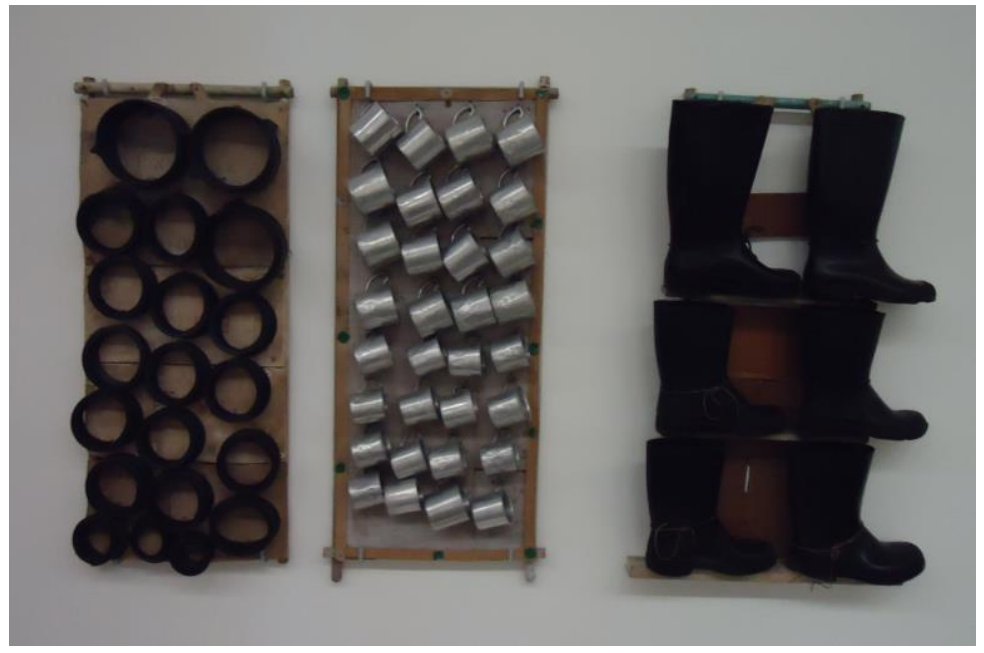

Figura 2 - Da esquerda para direita: Retentor de óleo, Canecas, e Botas.

Em Bispo do Rosário, o entrelaçamento das obras acontece nos bordados daquela que é a obra mais representativa de sua intuição

\footnotetext{
${ }^{7}$ Sobretudo, o entrecruzamento temático da memória autobiografada.

${ }^{8}$ De acordo com o Dicionário Oxford de Arte, já citado, a arte serial pertence ao "ramo da arte sistêmica no qual elementos simples e uniformes, que podem ser até produtos disponíveis no comércio, como tijolos, blocos de concreto etc., são dispostos segundo um princípio modular estrito. Carl Andre é um expoente destacado da arte serial” (2001, p. 488).
} 
artística, o "manto da apresentação", 9 o suntuoso manto que artista vestia quando era entrevistado ou fotografado pelo público. As obras de Bispo aparentemente possuem um desejo de utilidade, nesse sentido recordamos o fato de que ele não se via como um artista, mas como um escolhido divino para recriar "um mundo melhor" na terra através de suas obras e apresentá-lo a Deus no momento de sua morte. O "manto de apresentação" tanto era utilizado nas performances de Bispo, quanto deveria, segundo ele, servir de vestimenta mortuária no esperado "dia da passagem". Tinha como propósito deixar esta imagem do momento da passagem, pois desejava, assim, ser visto no momento da apresentação a Deus.

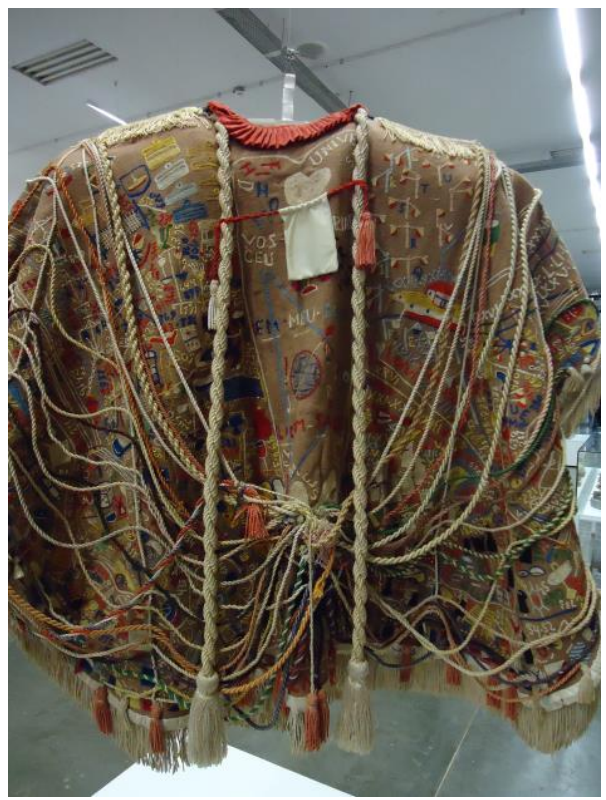

Figura 3 - O manto da apresentação ao Juízo Final, Tecido, fio e corda.

O "manto da apresentação" é um aglomerado de suas obras, por isso um entrelaçamento de suas criações. Nele temos miniaturas de objetos bordados por Bispo que foram confeccionados em forma de objetos

\footnotetext{
${ }^{9}$ A obra foi assim nomeada pelos curadores do "Museu Bispo do Rosário: arte Contemporânea" no momento de seu tombamento.
} 
palpáveis, tais como: as embarcações, o tabuleiro de xadrez, os cetros das misses etc. Quando observado de perto, pode-se desvendar os "segredos" do manto: por dentro temos diversos nomes de famílias que ele conheceu bordados com a linha azul dos uniformes desfiados que haviam sido utilizados pelos internos. Se, por fora, o cobertor bordado é colorido e chama a atenção por sua tonalidade avermelhada, por dentro, a cor azul e a sincronicidade dos nomes bordados revela uma uniformidade. Uniformidade esta contrária àquela que o artista não encontrava enquanto um sobrevivente em meio a uma sociedade que o excluía - o relegava a "objeto fora de uso digno de estar num quarto de despejo" como diria Carolina de Jesus ao se reportar a situação dos favelados do Canindé -, daí talvez a obsessão por nomear a utilidade dos objetos a seu redor neles próprios. Contudo, Carolina de Jesus parece se diferenciar de Bispo do Rosário ao gritar e pôr para fora suas mazelas e diante de sua incessante busca de seu reconhecimento. Bispo, por sua vez, parece gritar para dentro, para si, sendo legitimado como artista pelo grupo que o acompanhava.

A letra firme do bordado e os desvios gramaticais dessas escritas são mais um fator de aproximação entre Carolina de Jesus e Bispo do Rosário. A pouca escolaridade de ambos não os impediu de imprimir suas singularidades criativas no campo das artes, pelo contrário, a oralidade, a literariedade e os modos de vida transpostos para plasticidade trouxeram inovações e provocaram frestas nos cânones, ao trazer a voz dos oprimidos que inventaram suas próprias representações.

Não escapa à vista a lateral do manto, toda bordada com diversas cores como em uma moldura de um quadro, qual um pensamento de pintura sem pigmentos. Essas outras formas de exprimir a visualidade estão relacionadas às mudanças na arte moderna. Esse é um dos motivos pelos quais o artista pode ser considerado como um dos artistas que inaugura o pensamento de arte contemporânea do Brasil para o mundo.

Além dessa obra-vestimenta, temos o "fardão azul", uma veste tradicional dos imortais da Academia de Letras que foi subvertida por Bispo do Rosário em sua recriação. Nele vemos um fardão todo decorado com motivo floral e um tipo muito específico de bordado que lembra a escrita árabe. O inverso do casaco segue a mesma construção, com pontos em alto-relevo, precisamente bordados sem nenhum arremate. Nas mangas temos faixas de plástico reutilizado. É 
interessante notar o texto presente no casaco, no qual se LE a data do surto que o levou ao manicômio: "Eu vi im 22/12/1938".

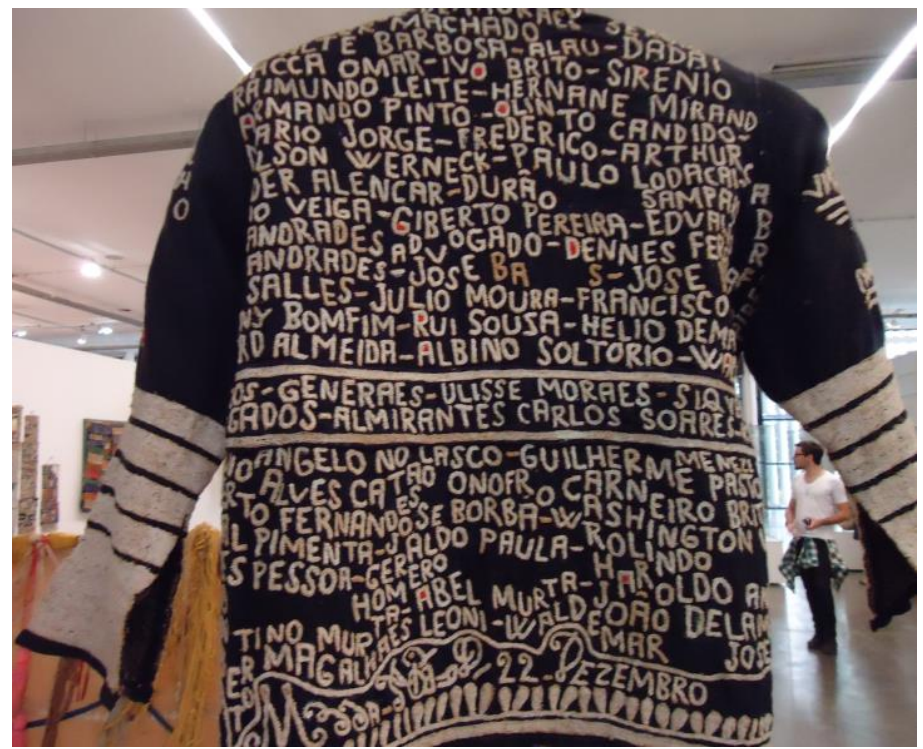

Figura 4 - Casaco bordado.

Dessa maneira, talvez possamos pensar que se o "manto da apresentação" marca o estágio máximo de sua produção do "mundo melhor", o casaco representaria sua inserção no universo da criação artística, como um membro que se senta pela primeira vez em sua cadeira na Academia de Letras. O tema da iniciação ao mundo das artes está presente em Carolina de Jesus nas cinco versões de seu texto intitulado "Prólogo" no original, publicado pela primeira vez em Journal de Bitita (1982) como "L'école" (Fernandez, 2015).

Como vemos, tanto Bispo quanto Jesus percorrem as histórias de suas vidas em sua obras, sentindo a necessidade de reafirmar uma outra história, criando e recriando histórias de si por meio da arte. Esse exercício de "escrita de si" é um procedimento comum nas artes, contudo, o que se percebe nos dois artistas não é a reprodução de um modelo autobiográfico tradicional, focado na primeira pessoa, antes, é uma forma de elaboração artística do mundo a partir de experiências pessoais. $\mathrm{O}$ conceito de 
escrevivência, ${ }^{10}$ tal como formulado por Conceição Evaristo, é outro exemplo de como isso se processa na ficção. Assim, em resposta à condição de marginalização, ao "reescrever" sua história por meio da arte, esses artistas constroem para si outro mundo possível.

Bispo do Rosário bordou grande quantidade de faixas e cetros semelhantes aos utilizados pelas misses. Nas faixas lemos nomes de diversos países e cidades, assim como em seus estandartes. Esses lugares apontados em suas produções cartografam os caminhos de sua vida, mostrando o potencial de sua memória ao recordar dos lugares por onde passou quando era marinheiro. De maneira semelhante, Carolina de Jesus não se cansava de recontar e inserir em sua ficção elementos de sua infância, tais como a paisagem e os costumes rurais experimentados nas cidades do interior de Minas Gerais e São Paulo por onde passou, lugares que reaparecem em seus contos, romances, provérbios, letras de música, diários e poesias.

Bispo do Rosário utilizava várias técnicas em uma mesma obra e aproveitava toda sorte de objetos que encontrava nas lixeiras, enquanto Carolina de Jesus lançava mão de vários gêneros literários e não literários em seus cadernos. Bispo bordava a frente e o verso de cada pedaço de pano com o mesmo cuidado com que a escritora favelada valorizava cada espaço do papel na composição de sua inscrição no mundo - chegando inclusive a partilhar seus textos em folhas que continham rabiscos de crianças às quais pertenciam antes alguns dos cadernos, ou anotações de comerciantes presentes em cadernos de contas reaproveitados na elaboração de sua poética de resíduos. ${ }^{11}$

\footnotetext{
${ }^{10}$ Tomo emprestado as palavras de Conceição Evaristo: "Sem dúvida alguma, a narrativa de Ponciá Vicêncio não se trata de minha biografia, como Becos da memória não é uma escrita verdadeiramente autobiográfica. Porém, toda a minha escrita, poemas, contos, romances e até ensaios, cumpre um ato de escrevivência. Assim como algumas das histórias escutadas no interior de minha família foram apropriadas como material narrativo para a escrita de Ponciá Vicêncio, a experiência do desfavelamento que sofri, as angústias de minha meninice e de minha adolescência aparecem em Beco da memória. A composição da personagem Maria Nova muito se con(funde) com a história pessoal do meu eu menina. Inventar Maria Nova foi inventar a razão de minha escrita (Evaristo, 2014, p. 31).
}

${ }^{11}$ Este conceito foi amplamente desenvolvido em minha tese sobre a escritora (Fernandez, 2015). 


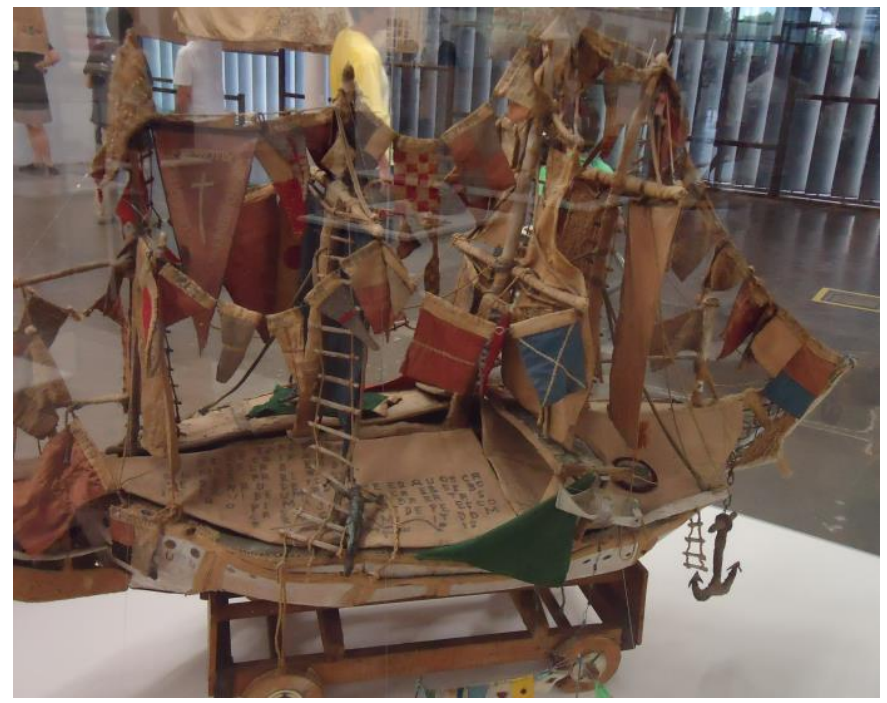

Figura 5 - Veleiro.

Como se vê, os artifícios utilizados pelos artistas sucateiros dependiam do material disponível. Algumas vezes, Bispo do Rosário escrevia à caneta, noutras bordava sem rascunhos diretamente no retalho de tecido, porém sempre com perfeição. Ele não utilizava pincéis, suas ferramentas eram objetos do cotidiano, tais como, colheres e objetos utilizados por pedreiros. Carolina de Jesus lia livros e jornais retirados do lixo, assim como escrevia sobre folhas de papel de pão, em sobras de cadernos escolares, em blocos de papel de contas encontrados nas lixeiras das fábricas de onde retirava o sustento para vivenciar seu devir-escritora. A forma de seu texto é bastante complexa, não havendo um parâmetro de organização em seus manuscritos, assim como não havia em Bispo uma sequência formal. Em um mesmo caderno ou até no curto espaço de uma mesma folha é possível encontrar até três gêneros ou assuntos lançados pela escritora no fervor de sua inspiração-indignação.

Assim como Bispo do Rosário costurava sua fé religiosa em estandartes, Carolina de Jesus mescla diversos gêneros literários em seus Provérbios (1963), carregados de um tom religioso.

$\mathrm{Na}$ produção de Bispo do Rosário, figura o apego às cenas do cotidiano, o dia a dia costurado em trapos, que lembram os autógrafos 
de Jesus, caracterizados por uma miscelânea de gêneros e discursos reunidos num memorial-mosaico de retalhos de acontecimentos.

Há uma obra sem título na qual Bispo do Rosário retira a moldura de um quadro velho e reconstrói a tela rearranjando retalhos com pequenos textos bordados, nos quais constam códigos seguidos de indicações da materialidade de suas obras: "8.026. papeis de varias cores por um metro", "8.027. Retalhos de panos com varias cores tipos", "10.33. Bolsa pintada de vernies preta 24 por 20 de largo tem uma no centro costurada 10 por 11. É". Durante todo o percurso da obra, o artista vai delineando os passos de sua criação. São apontamentos, pistas, semelhantes às marginálias presentificadas nos originais de Carolina de Jesus, que pouco a pouco permitem ao leitor conhecer melhor o todo de suas obras. A obra de Bispo a seguir (figura 6) parece ser a materialização dos manuscritos de Jesus.

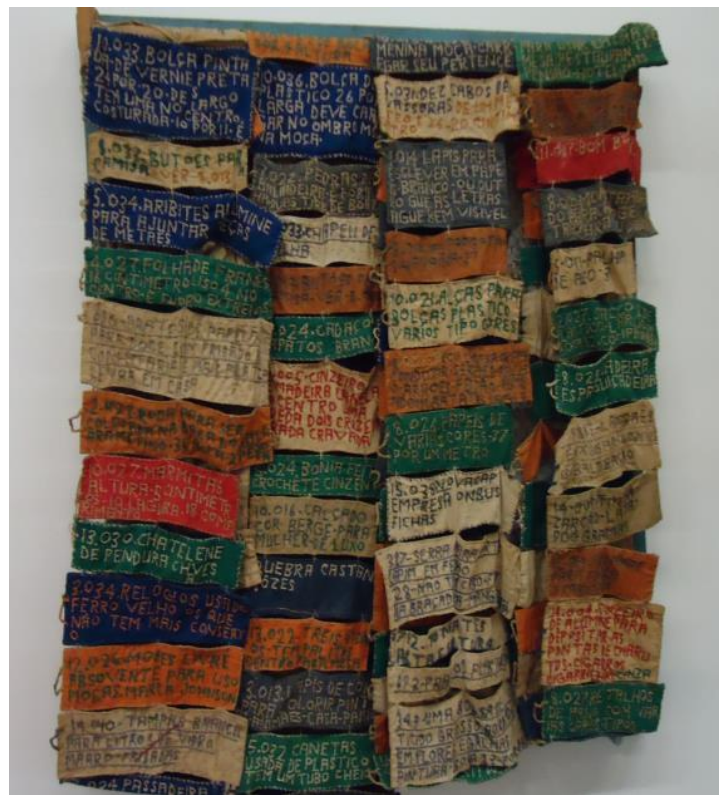

Figura 6 - Bordados.

Vale acentuar que, nessa obra, Bispo do Rosário utiliza retalhos soltos e fluidos, com tridimensionalidade, procedimento utilizado pelo movimento concretista brasileiro, que, mais tarde, viria a reaparecer nas 
obras de Aluísio Carvão e de Hélio Oiticica. Bispo e Carolina são artistas que vivenciam em suas obras devires-trapeiros (Fernandez, 2015, p. 263), que tecem rastros contaminados pela prosa cotidiana, inventada de maneira quase orgânica, sem a funcionalidade estética do gosto-artístico socialmente aceito. No entanto, nos dias de hoje, com a evolução da percepção sobre a arte, eles têm sido aproximados das vanguardas artísticas e inseridos nos debates artísticos como precursores de autênticas obras dessacralizadoras.

Essas obras-limite permitem não somente aproximar os dois artistas nos movimentos de suas criações, como faz pensar na literatura e na pintura produzida por artistas colocados às margens da sociedade, nos processos criativos realizados através de fluxos partidos que possuem uma organicidade muito específica: poéticas de sucatas marcadas pela repetição. Tanto Bispo do Rosário quanto Carolina de Jesus tecem incessantemente espaços de rememoração ou até de celebração de seus passados em cidades pouco urbanizadas. No entanto, ambos recorrem ao passado rural como forma de contestação à cidade "modernizante", reinserindo-se através de suas obras no meio social que os oprime e exclui.

Diversos são os momentos em que Carolina de Jesus relembra sua infância: bailes, costumes escolares, trajetos da educação familiar e religiosa e, fundamentalmente, a relação entre brancos e negros na pequena cidade de Sacramento. Nos momentos de surto criativo, Bispo do Rosário rendia-se ao enclausuramento - uma das "formas de tratamento" comum nas instituições psiquiátricas tradicionais - munido de uma agulha e dos fios do uniforme de interno, que desfiava para retecer através de bordados seu passado em Sergipe. Seus mantos são marcados por festas tradicionais sergipanas como as congadas, as marujadas e as folias de reis. Esses traços de rememoração, em Carolina de Jesus e em Bispo do Rosário, constituem-se como base para o reconhecimento e a formação desses si enquanto sujeitos históricos.

Hoje Bispo do Rosário é comparado a Marcel Duchamp e Andy Warhol, artistas plásticos que também ressignificam objetos de utilização cotidiana transformando-os em obra de arte e revelando que o fazer artístico se situa em outra dimensão, que ultrapassa a condição material que os separa. Sobretudo a obra "a roda", de Bispo, rende comparações com a obra "A roda de bicicleta", de Duchamp (Lhullier, 2011, p. 9). Independentemente de filiações que possam vir a legitimar as obras de Bispo do Rosário, seus trabalhos são simbólicos, tocam por sua 
capacidade de dispor dos objetos; por seu trabalho no entalhe da madeira, lembrando xilogravuras; por sua impecável habilidade no bordado de alto-relevo, que faz parte da tradição das bordadeiras sergipanas; e pela escolha das cores de tom tropical, que o identificam ao Brasil.

A improvisação, atrelada ao aspecto oral que marca essas obras, aparece como elemento da poética de sucatas por eles desenvolvida, seja em Carolina de Jesus, ao variar as versões de um mesmo "causo", ou em Bispo do Rosário, ao escarafunchar sua história através dos resquícios de suas lembranças. A poética oral transposta não pode ser tomada apenas pela letra ou obra plástica; para compreendê-la, é preciso se valer das vozes que nortearam as veredas dessas produções. Esse mecanismo ocorre a tal ponto que, no contar de Jesus, a voz se sobrepõe à letra, por exemplo, na musicalidade presente nos textos de Jesus, na entonação própria da dicção de uma mulher do interior de Minas Gerais, bem como nos momentos em que a escritora reproduz a fala dos vizinhos nordestinos, portugueses, ciganos ou espanhóis.

Bispo do Rosário, por sua vez, improvisa ao registrar o cotidiano da Colônia, tanto quando dispõe obsessivamente numa sequencia diversos tênis congas de cor azul utilizados pelos enfermeiros do manicômio quanto quando agrupa determinados objetos que remetem a uma cena, como na assemblage intitulada "macumba". Nessas poéticas de sucatas, a elaboração e o improviso caminham lado a lado, pois os modos de composição variam de acordo com as situações e a disponibilidade do material-sucata a ser manipulado.

Em meio a condições de subexistência, ambos os artistas criaram e reconstruíram pedaços de seus cotidianos, inventando outros sentidos para suas histórias. Nesse movimento marcado por um devir-artista, colocaram em funcionamento máquinas-obras (como Duchamp denominou suas obras feitas para a mente e não mais para os olhos) que deixaram para o futuro formas mobilizadas, desterritorializadas pelo "povo que faltava", na acepção de Deleuze (1997). Desse modo, suas criações ultrapassam o modelo autobiográfico, pois revelam o sentimento de homens desvislumbrados com a modernidade, seres desfacelados, partidos, líquidos na esteira das análises de Bauman (2001) ao pensar a pós-modernidade.

Autodidatas, enquanto Bispo do Rosário transformou sua cela em ateliê, Carolina de Jesus adaptou seu "quarto de despejo" e fez emergir suas atividades literárias. Obras com estruturas ambíguas, ambivalentes, 
complexas e variadas, que se valem dos mesmos recursos utilizados por outros artistas na disposição de seus manuscritos ou objetos, como vemos na separação, na seleção, na codificação e nas marginálias da escritora favelada, processo também presente na obra do artista plástico, em especial nas obras que denominamos como cenas do cotidiano.

De certo modo eles transformaram suas vidas em obra de arte, modularam formas de viver, catalogaram, esquadrinharam, nomearam pessoas e inventariaram mundos. Enriqueceram, assim, o aprendizado e as invenções de si, materializados por meio da máquina da memória e do espírito quixotesco que os guiaram suas criações.

Pode-se dizer que a criação que nasce do meio popular pelas mãos de Bispo e Jesus parte da repetição e recriação da oralidade de suas histórias, da reutilização de sucatas, da reunião dos farelos de si recolhidos e semeados por esses artistas-artesãos na reprodução do gesto, mas, sobretudo, na sua renovação: repetir para recriar e reinscrever suas realidades. Suas obras podem, inclusive, apontar para uma emancipação social, abrindo caminho para a emancipação das obras elaboradas em hospícios, por não letrados, sujeitos esquecidos em suas solidões e marginalidades.

Os trabalhos de Bispo do Rosário e de Carolina de Jesus revelam, ainda, a condição dilacerada do intelectual-artista da periferia da América Latina, contextualizando e explorando elementos vitais e pulsantes de outra história e outros preceptos estéticos considerados "menores". Diferentemente dos "grandes" intelectuais que incorporaram a cultura popular nas artes para revelar uma qualidade ética-estética brasileira, temos aqui as potências de duas poéticas das sucatas, que revelam em que medida os mecanismos de funcionamento da máquina da oralidadememória brasileira cresce ao lado da literatura e das artes plásticas.

\section{Referências}

BAUDRILLARD, Jean (1985). À sombra das maiorias silenciosas: o fim do social e o surgimento das massas. São Paulo: Brasiliense.

BAUMAN, Zigmund (2001). Modernidade líquida. Tradução de Plínio Dentzien. Rio de Janeiro: Zahar, 2001.

DELEUZE, Gilles (1997). Crítica e clínica. Tradução de Peter Pál Pelbart. São Paulo. Editora 34. 
DICIONÁRIO OXFORD DE ARTE (2001). Edição de Ian Chilvers. Tradução de Marcelo Brandão Cipolla. São Paulo: Martins Fontes.

EVARISTO, Conceição (2014). Nos gritos d'Oxum quero entrelaçar minha escrevivência. In: DUARTE, Constância Lima et al. (Org.). Arquivos femininos: literatura, valores, sentidos. Florianópolis: Mulheres, p. 25-33.

FERNANDEZ, Raffaella A. (2015) Processo criativo nos manuscritos do espólio literário de Carolina Maria de Jesus. Tese (Doutorado em Teoria e História Literária) - Universidade Estadual de Campinas, Campinas. Disponível em: https://goo.gl/fbWsWy. Acesso em: 10 abr. 2016.

JESUS, Carolina Maria de (1960). Quarto de despejo: diário de uma favelada. São Paulo: Francisco Alves.

JESUS, Carolina Maria de (1963). Provérbios. São Paulo: Luzes.

JESUS. Carolina Maria de (1982). Journal de Bitita. Tradução de Régine Valbert. Paris: A. M. Métailié.

LHULLIER, L. A. (2011). Bispo e Duchamp: a diferença na ponta da língua. Opção Lacaniana On-line, ano 2, n. 4. Disponível em: https://goo.gl/xE7tsG. Acesso em: 10 abr. 2016.

PRISIONEIRO DA PASSAGEM. Direção de Hugo Denizarte. Rio de Janeiro: CNPI, 1982. DVD (30 min22seg). Disponível em: https://goo.gl/Sv1j0D. Acesso em: 11 out. 2016.

Recebido em março de 2016.

Aprovado em junho de 2016.

\section{resumo/abstract/resumen}

\section{Carolina Maria de Jesus e Arthur Bispo do Rosário: uma poética de sucatas na construção da identidade artística}

Raffaella Andréa Fernandez

Avessos a expressões que conviveram às margens do processo de modernização dos "anos dourados" brasileiro da primeira metade do século XX, Arthur Santo Bispo do Rosário (1910-1984) se desloca de Sergipe para o Rio de Janeiro e Carolina Maria de Jesus (1914-1977) de Minas Gerais para São Paulo. O artista plástico manteve-se imerso em linhas, trapos e diversos tipos de sucatas, enquanto a escritora debruçava-se sobre jornais, livros e cadernos, materiais 
miraculosamente selecionados e retirados das latas de lixo, entre outros resíduos que lhes serviam de substância ou suporte por excelência a seus procedimentos criativos. Ambos produziram e cultivaram suas poéticas de sucatas como mecanismo de inserção, reafirmação e eclosão em um mundo excludente. Esses artistas expressam procedimentos artísticos criativos e de potência equivalente a dos movimentos artísticos modernos e pós-modernos, assumindo em suas criações o rompimento e a colisão com os sistemas linguístico e visual ao incorporar a arte ao lixo, ao descartável, à sucata.

Palavras-chave: Arthur Bispo do Rosário, Carolina Maria de Jesus, poéticas de sucatas.

\section{Carolina Maria de Jesus and Arthur Bispo do Rosario: a poetics of waste in the construction of artistic identity}

Raffaella Andréa Fernandez

Resisting aesthetic expressions that came about in the wake of Brazil's modernization process, during the "golden years" of the first half of the twentieth century, Arthur Santo Bispo do Rosario (1910-1984) moves from Sergipe to Rio de Janeiro and Carolina Maria Jesus (1914 -1977) from Minas Gerais to São Paulo. While Bispo do Rosario employed yarn, cloth and various types of waste materials, Carolina Maria de Jesus used newspapers, books, notebooks and materials that she carefully selected from the trash she collected. For both the artist and the writer, these waste products were at the same time substance and primary materials in their creative endeavors. Both used waste as a means of inserting and reaffirming their work within the confines of an exclusionary society. These artists' work expresses aesthetic and creative procedures that fit within the parameters of modern and postmodern art. Their work challenges prevalent linguistic and visual systems by incorporating waste, garbage, and disposable materials.

Keywords: Arthur Bispo do Rosario, Carolina Maria de Jesus, artistic identity, poetics of waste.

\section{Carolina María de Jesús y Arthur Bispo do Rosario: una poética de residuos en la construcción de la identidad artística}

\section{Raffaella Andréa Fernandez}

En contravía con las expresiones que convivieron en los márgenes del proceso de modernización brasileña de los "años dorados" de la primera mitad del siglo XX, Arthur Santo Bispo do Rosario (1910-1984) se traslada desde Sergipe a Río de Janeiro y Carolina María de Jesús (1914 -1977) desde Minas Gerais a São 
Paulo. El artista plástico se mantuvo inmerso entre hilos, trapos y diversos tipos de materiales de desecho, mientras que la escritora se inclinaba por periódicos, libros, cuadernos y materiales milagrosamente seleccionados y retirados de los botes de basura, entre otros residuos que les servían como su sustancia o apoyo por excelencia a sus procesos creativos. Ambos produjeron y cultivaron su poética de residuos como mecanismo de inserción, reafirmación y eclosión en un mundo de exclusión. Estos artistas expresan procedimientos artísticos y creativos de una potencia equivalente al de los movimientos del arte moderno y posmoderno, asumiendo en sus creaciones la ruptura y la colisión con los sistemas lingüísticos y visuales al incorporar los residuos, la basura y lo desechable en su arte creativo.

Palabras clave: Arthur Bispo do Rosario, Carolina María de Jesús, identidad artística, poética de residuos. 